\title{
RETRATO DA EDUCAÇÁO DO CAMPO: REALIDADE DA ESCOLA MUNICIPAL SAGRADO CORAÇÃO DE JESUS DE VILA RICA/MT
}

\author{
Maria Josiane Aragão Feitosa ${ }^{1}$ \\ Marcelo Franco Leão ${ }^{2}$
}

\begin{abstract}
Resumo: As escolas do campo enfrentam lutas diárias para promover uma educação de qualidade. Esse estudo teve como objetivo conhecer a opinião de estudantes e professores de uma escola do campo mato-grossense em relação a maneira com que o ensino vem sendo ofertado nas salas multisseriadas e assim retratar a real situação dessa escola. O estudo, de caráter descritivo e exploratório e abordagem qualitativa, configura-se como um estudo de caso. A investigaçáo foi desenvolvida na Escola Municipal Sagrado Coração de Jesus, que é uma escola localizada na zona rural no Projeto de Assentamento Santo Antônio da Beleza, no município de Vila Rica/MT. Para coletar dados foi aplicado um questionário para os estudantes e outro para os professores, seguida pela produçáo de uma imagem que retratasse a realidade escolar desta escola, sendo que todos esses dados foram posteriormente analisados. As reflexôes permitiram constatar que são diversos os desafios da Educação do Campo, sendo um deles a falta de infraestrutura adequada e a constante ocorrência de turmas multisseriadas. As reflexóes indicam que o professor precisa voltar-se para a realidade do campo, direcione suas metodologias para as demandas rurais. Logo, para que a escola do campo atenda às necessidades contemporâneas é preciso oportunizar aos estudantes uma educaçáo satisfatória e que estes possam desenvolver o senso crítico e exercer sua cidadania.
\end{abstract}

Palavras-chave: Desafios, Educação do Campo, Realidade escolar.

\section{PORTRAIT OF FIELD EDUCATION: REALITY OF THE SAGRADO CORAÇÃO DE JESUS MUNICIPAL SCHOOL OF VILA RICA/MT}

Abstract: Schools in the countryside face daily struggles to promote quality education. This study aimed to know the opinion of students and teachers of a rural school in Mato Grosso regarding

1 Graduação em Pedagogia pela UNEMAT. Especialização em Educação do Campo pelo IFMT Campus Confresa. Professora da Rede Municipal de Ensino de Vila Rica/MT.

2 Graduado em Licenciatura em Química (UNISC)e em Física (UNEMAT). Pós-graduado em Orientação Educacional(Dom Alberto) e em Relaçóes Raciais na Educação e na sociedade Brasileira(UFMT). Mestre em Ensino (UNIVATESS). Doutor em Educação em Ciências (UFRGS). Professor do IFMT Campus Confresa-MT. 
the way in which teaching has been offered in the multi-seried classrooms and thus portray the real situation of this school. The study, of a descriptive and exploratory character and qualitative approach, is configured as a case study. The research was developed at the Sagrado Coração de Jesus Municipal School, which is a school located in the rural area of the Santo Antônio do Beleza Settlement Project, in the municipality of Vila Rica/MT. To collect data a questionnaire was applied to the students and another to the teachers, followed by the production of an image that portrayed the school's reality, and all this data was later analyzed. The reflections allowed us to verify that there are several challenges in the field education, one of them being the lack of adequate infrastructure and the constant occurrence of multi-seried classes. The reflections indicate that the teacher needs to turn to the reality of the field, to direct his methodologies to the rural demands. Therefore, for the rural school to meet contemporary needs, it is necessary to provide students with a satisfactory education and that they can develop a critical sense and exercise their citizenship.

Keywords: Challenges, Field Education, School reality.

\section{INTRODUÇÁO}

A Educação do Campo pode ser considerada uma conquista dos movimentos sociais, a partir do século XX, que colabora com a permanência dos homens e mulheres no campo. Essa conquista foi consolidada e garantida oficialmente pela Lei de Diretrizes e Bases da Educação Nacional (LDBEN), No 9394/96, em seu Artigo 28. Este assegura a oferta da Educação Básica para a população do campo ao afirmar que os sistemas de ensino deverão fornecer adaptaçôes necessárias para adequar-se às peculiaridades da vida do campo (BRASIL, 1996).

Contudo, essa modalidade de ensino passa por muitos desafios que necessitam ser refletidos e enfrentados visando proporcionar condiçóes de aprendizagem àquelas pessoas que residem ou vivem no campo. Algumas das problemáticas mais evidentes nas escolas do campo consistem na falta de estrutura, aparelhamento e profissionais qualificados. Estas escolas deveriam ter uma atenção especial, a fim de atender as especificidades do público que atendem, mas a realidade é completamente diferente (ZEFERINO, 2014).

Entretanto, os problemas supracitados não são novos. Ao analisar a trajetória da Educação no Campo, é possível reconhecer que essa política pública nasceu de conflitos e lutas que foram imprescindíveis para garantir os direitos das pessoas a uma educação de qualidade que não descuidasse do contexto e das práticas desses sujeitos, ou seja, respeitando suas peculiaridades (CALDART, 2002). De acordo com Zeferino (2014), ainda são muitos os desafios que impedem os avanços no atendimento especializado, o que dificulta a consolidação da Educação do Campo.

No contexto brasileiro, outro grande desafio da Educação do Campo é o êxodo rural. Segundo Silva (2018), nas últimas décadas, o campo vem diminuindo expressivamente sua população, especialmente os jovens, o que torna essa desintegração um sério e preocupante problema. Essa é uma situação de grande amplitude, pois a permanência do homem no campo é resultado de um conjunto de açóes que possibilitam as condiçóes mínimas de sobrevivência em determinados 
espaço e tempo. Essas garantias perpassam por políticas públicas destinadas as questóes fundiária, educacional, social bem como a geração de trabalho e renda.

Um dos fatores que mais favorece ao êxodo rural de jovens é a falta de oportunidades de trabalho remunerado e a dificuldade de continuar os estudos no campo. Essa situação provoca um baixo número de alunos nas escolas rurais e, como consequência, provoca a existência das chamadas turmas multisseriadas. Essas turmas reúnem alunos de diferentes etapas de escolarização em um mesmo ambiente, os quais são atendidos por um mesmo professor e, por vezes, tem menos oportunidades de contemplar os conteúdos e informaçôes.

Diante de todos os desafios apresentados, a questáo que norteou essa pesquisa foi: $\mathrm{O}$ que pensam os alunos e professores da Escola Municipal Sagrado Coração de Jesus, em Vila Rica/MT, sobre o formato condensado/modular que vivenciam em salas multisseriadas? Assim, o presente estudo teve como objetivo conhecer a opiniáo dos alunos e professores de uma escola do campo mato-grossense em relaçáo ao modo que o ensino vem sendo ofertado nas salas multisseriadas retratando a real situação dessa escola.

\section{REFLEXÓES TEÓRICAS SOBRE A EDUCAÇÃO DO CAMPO}

A Educaçáo do Campo nasceu com o objetivo de valorizar o povo brasileiro que trabalha e vive no campo. Nesse sentido, ela é uma crítica ao modelo convencional de educação brasileira, principalmente por não serem respaldadas as necessidades educacionais e formativas do povo que trabalha e vive no campo.

Acerca deste assunto, assinala Caldart (2009, p. 39), que:

Essa crítica nunca foi à educação em si mesma porque seu objeto é a realidade dos trabalhadores do campo, o que necessariamente a remete ao trabalho e ao embate entre projetos de campo que tem consequência educacional e o projeto de país [...]. E tratou-se primeiro de uma crítica prática: lutas sociais pelo direito à educaçáo, configuradas desde a realidade da luta pela terra, pelo trabalho, pela igualdade social, por condiçóes de uma vida digna de seres humanos no lugar em que ela aconteça.

Observa-se que a Educação do Campo não nasceu como uma crítica apenas de denúncia, mas sim apontando alternativas, formando ideias de transformaçóes e incentivando a permanência destas pessoas nas zonas rurais. O Programa Nacional de Educação do Campo (PRONACAMPO) estabelece alguns critérios para se entender a Educação do Campo, o documento diz que:

Compreende-se como "Educação do Campo" a Educação Básica em suas etapas de Educaçáo Infantil, Ensino Fundamental, Ensino Médio e Educação Profissional Técnica de nível média integrada ao Ensino Médio, com a finalidade de atender às populaçóes do campo em suas mais variadas formas de produção da vida - agricultores familiares, extrativistas, pescadores artesanais, ribeirinhos, assentados e acampados da reforma agrária, quilombolas, caiçaras, indígenas e outros (BRASIL, 2013, p. 4). 
Entre suas áreas de abordagem, a Educação no Campo contempla: agroecologia, iniciação científica, educação em direitos humanos, cultura, arte popular, esporte e lazer, memória, história dos povos e comunidades tradicionais. Assim, a identidade da escola do campo se caracteriza por sua vinculação às demandas próprias da realidade dos trabalhadores, valorizando os saberes, culturas e identidades, permitindo a representatividade desses brasileiros.

A Educação do Campo toma posição, atua desde uma particularidade, mas com caráter universal almeja alcançar sua inclusão tanto na educação como no projeto de sociedade. Ela "nasce da 'experiência de classe' de camponeses organizados em movimentos sociais e envolve diferentes sujeitos, às vezes em diferentes posiçóes de classe" (CALDART, 2009, p. 38).

Para a autora supracitada, a Educação do Campo, nasceu de uma tentativa de revolucionar o modelo hierarquizado de educaçáo tradicional adentrando no terreno das políticas públicas, conflitantes com o Estado. Sabe-se que Estado brasileiro defende projetos de manutenção de privilégios para uma parte da sociedade, modelo este que é combatido pelos movimentos sociais. Mesmo a escola se centrando na própria localidade, ela pretende ir além das estruturas constitutivas, buscando atingir outras dimensões enquanto projeto educativo e discutindo pautas mais abrangentes. A Educação do Campo luta para que a noção de educação que orienta suas práticas seja descentralizada da escola e para que os trabalhadores tenham acesso ao conhecimento produzido na sociedade.

É interessante notar que a Educaçáo do Campo, além de colocar o trabalhador no centro da construção do conhecimento, também problematiza e critica o modelo vigente de educaçáo dominante. No entanto, segundo Sousa e Machado (2018), muitos são os questionamentos sobre trabalhar a partir da realidade dos alunos visto que muitos equívocos em adotar essa estratégica seriam limitantes. Nas palavras dos autores:

É importante reafirmar que, referenciar o currículo na realidade do campo, náo significa estudar apenas a realidade local, ela é tomada como o ponto de partida, como elemento a ser problematizado, por afetar efetivamente a vida dos estudantes e de suas comunidades (SOUSA; MACHADO, 2018, p. 07).

Considera-se que, ao trabalhar conteúdos do cotidiano, os alunos podem atribuir maior significado para os diversos tipos de conhecimentos e é compreendendo a sua própria realidade que poderáo vir a transformá-la. Para que isso aconteça, Marques (2017) defende que para atender essas especificidades os professores precisam de formaçáo ampla e diferenciada, com capacidade de desenvolver um trabalho transdisciplinar. Essa ação não depende somente do profissional em específico, mas também da organização da própria universidade.

Nessa perspectiva, Marques (2017, p. 732) afirma que:

Os projetos de formaçáo de educadores do campo devem, portanto, oportunizar espaços formativos que extrapolem os muros das universidades, que levem o discente a interagir com a diversidade do campo, com os seus saberes e formas de construção e apropriação do conhecimento. 
Assim, entendemos a necessidades de bons investimentos formativos para que alcancemos, de fato, as especificidades do público atendido. Dentre as políticas públicas colaborativas com a Educaçáo do Campo, podemos citar o Programa Nacional de Educação na Reforma Agrária (Pronera), instituído pelo por meio do Decreto no 7.352, de 4 de novembro de 2010 e o Programa Nacional de Educaçáo do Campo (Pronacampo) pela Portaria no 86/2013 PIBID diversidade.

Nas palavras de Freire (2006, p.137) "As condiçóes materiais em que vivem os educandos lhes condicionam a compressão do próprio mundo, sua capacidade de aprender, de responder aos desafios". Referente às questôes metodológicas, sugestivas para a modalidade, uma mais recorrente é a pedagogia da alternância. Esta possui uma organizaçáo curricular voltada para projetos de intervençáo em comunidades. Os estudantes ficam incumbidos em desenvolver atividades práticas, estágios supervisionados, realizar relatórios do tempo comunidade, integrando a pesquisa e o ensino de extensáo. Este método promove a integraçáo de saberes entre escola e comunidade construindo um conhecimento significativo para os envolvidos.

Em consonância com Freire (2006), compreende-se que, ao respeitar a realidade do educando podemos dinamizar o processo de mediação e, consequentemente, colaborar com construçáo do conhecimento (ensino e aprendizagem) de forma significativa. Conforme Marques (2017), a proposta pedagógica indicada para as escolas do campo requer uma abordagem que assuma o contexto dos sujeitos envolvidos e que privilegie metodologias específicas, voltadas à diversidade sociocultural e linguística dos alunos do campo.

Nesse sentido, podemos afirmar que a proposta pedagógica da Educaçáo no Campo precisa ser elaborada com a participação da sociedade, pois ela "tem como base a realidade dos povos do campo e quilombola e a especificidade da organização e oferta da educação básica às comunidades rurais" (MARQUES, 2017, p. 23). Em outras palavras, a equipe escolar precisa respaldar o interesse coletivo visando o bem comum para a vivência e permanência em comunidade.

\section{PROCEDIMENTOS METODOLÓGICOS}

O presente estudo possui caráter descritivo e exploratório, e abordagem qualitativa. Esta metodologia é definida por Lakatos e Marconi (2013, p. 57), por sua capacidade de colocar o pesquisador em contato direto com tudo o que foi escrito, dito ou filmado sobre a temática.

Assim, este estudo foi desenvolvido mediante a abordagem qualitativa, por entender que esse tipo de abordagem é extremamente viável por permitir desvelar os significados presente na realidade social. Para Minayo e Deslandes (2011, p. 21) "a pesquisa qualitativa responde a questóes muito particulares. Ela se ocupa, nas Ciências Sociais, com um nível de realidade que não pode ou não deveria ser quantificado". Esse tipo de abordagem difere da abordagem quantitativa, que trabalha a partir de estatísticas e significâncias para compreender os fenômenos. 
A proposta foi desenvolvida na Escola Municipal Sagrado Coração de Jesus, que está localizada no município de Vila Rica/MT, criada pelo Decreto no 080/89 de 09 de junho de 1989. Esta unidade escolar é mantida pela rede Oficial de Ensino da Prefeitura Municipal, por meio da Secretaria Municipal de Educação. A Escola situava-se no Projeto "Aracati I" - zona rural, localizado a $18 \mathrm{~km}$ da sede do Município.

Cabe ressaltar que o êxodo rural atingiu o projeto "Aracati I, II e III", e isso diminuiu a demanda para esta escola. De acordo com dados da gestáo pública local, era inviável continuar mantendo o atendimento nesse local tendo em vista o pequeno número de matriculados. No início do ano 2014, os estudantes que eram atendidos nesta escola foram conduzidos para unidades escolares da zona urbana. Com isso, a sede da Escola Municipal Sagrado Coração de Jesus mudou-se para Projeto de Assentamento Santo Antônio do Beleza.

Atualmente a unidade oferece Educação Infantil, Ensino Fundamental de 09 anos (modalidade denominada regular) e Ensino Fundamental na modalidade da Educação de Jovens e Adultos (EJA). Compartilha, ainda, as instalaçóes com a Escola Estadual Vila Rica que oferece o Ensino Médio, nas modalidades EJA e Regular. Atende, também, todos os alunos da Educação Básica.

O Projeto Político Pedagógico da Escola favorece o compromisso com a educaçáo como processo formativo ético, político e social dos educandos, respeitando seus saberes e o meio no qual vivem para a transformação social. E assim, "contribuir para a definição de sua identidade de escola do campo e para a construção de um mundo mais justo, mais humano e democrático onde as pessoas possam viver inspiradas pelos valores de liberdade, solidariedade e respeito mútuo" (PPP, 2016, p. 51).

Trata-se de valorizar e ampliar dos seus próprios conhecimentos, estruturando os pontos norteadores da ação docente no sentido de formar pessoas intelectuais e moralmente autônomas, que sejam livres para refletir, questionar, criticar e transformar a realidade na qual estáo inseridos. A Escola ainda estimula a participaçáo da comunidade na construção da cidadania e dos valores que são imprescindíveis na construção de uma sociedade mais fraterna, solidária, que valorize o ser humano.

O objetivo principal da instituição é "proporcionar ao educando condiçôes para o desenvolvimento de suas potencialidades, através de uma educação consciente e inovadora. Para isso, mediante a realidade local, o induz na busca contínua, do crescimento pessoal, espiritual, cultural e social” (PPP, 2016, p. 51). Todavia, além de ensinar e transmitir conteúdo a Escola almeja envolver os alunos numa reflexão sobre os valores que envolvem a vida, a cultura, e as identidades da comunidade.

O projeto de Assentamento Santo Antônio do Beleza fica localizado, aproximadamente, à $45 \mathrm{~km}$ da cidade de Vila Rica/MT. As estradas de acesso ao local são precárias, impossibilitando que professores venham da cidade, diariamente, para trabalhar na escola. Esta situação leva os professores a residirem no assentamento. Além disso, a escola que antes era apenas uma sala anexa de uma outra escola da cidade, não possui uma estrutura física adequada em diversos aspectos. 
Diante do contexto mencionado anteriormente, muitos professores passaram pela escola sem permanecer, o que causou uma rotatividade docente muito grande. Além disso, muitos professores sem formação específica atuaram na escola, o que desfavorece a abordagem e explanaçáo dos conteúdos. Essa situaçáo pouco mudou, conforme descrito no Quadro 1, que mostra a formação e a atuação dos professores da Escola Municipal Sagrado Coraçáo de Jesus.

Quadro 1: Características das professoras da Escola Municipal Sagrado Coração de Jesus

\begin{tabular}{|c|c|c|c|}
\hline Nome & Situaçáo funcional & Formaçáo & Atuação \\
\hline Professora A & Efetiva & $\begin{array}{c}\text { Pedagogia e Ciências } \\
\text { Sociais }\end{array}$ & Matemática \\
\hline Professora B & Contrato temporário & Pedagogia & Educação Infantil \\
\hline Professora C & Contrato temporário & Educação Física & $\begin{array}{c}\text { Português e Educação } \\
\text { Física }\end{array}$ \\
\hline Professora D & Contrato temporário & $\begin{array}{c}\text { Ensino médio } \\
\text { propedêutico/ acadêmica } \\
\text { do curso de zootecnia }\end{array}$ & Ciências, História e Inglês \\
\hline Professora E & Contrato temporário & Pedagogia & $\begin{array}{c}\text { Geografia, Educação } \\
\text { Artística e Ensino } \\
\text { Religioso }\end{array}$ \\
\hline
\end{tabular}

Fonte: Dados coletados na pesquisa (2019).

Neste quadro observa-se que somente a professora que atua na Educação Infantil trabalha na sua área de sua formação. Também demonstra que a professora $\mathrm{D}$ não possui formação acadêmica na área educacional.

Para coletar os dados, foram realizadas investigaçóes com as professoras e com os alunos da escola, além de ser registrada uma situação do contexto dessa escola por meio de uma fotografia, para análise. Para garantir o anonimato dos participantes, os nomes foram substituídos por letras. Todos os dados coletados com os investigados foram apresentados em itálico para facilitar a identificaçáa. Cabe ressaltar que a escola emitiu "Carta de Anuência" autorizando o estudo após observado o projeto de pesquisa. Ademais, todos os envolvidos concordaram em participar voluntariamente da pesquisa. Por cuidados éticos e por se tratar de pessoas menores de idade, a face dos estudantes foi omitida na Figura.

A análise das respostas das professoras e dos estudantes se deu por meio da abordagem qualitativa, a qual considera a subjetividade dos sujeitos envolvidos na investigação (LAKATOS; MARCONI, 2013). Já o registro fotográfico de uma situação real do ambiente escolar, só foi possível devido à análise dessa imagem e dos discursos nela envolvidos. Náo se trata apenas de uma fotografia de um lugar específico e um determinado momento, mas sim de um contexto por ela revelado. 
Essa metodologia é semelhante àquela utilizada por Leão et al. (2014), que usaram uma imagem para refletir sobre a transação entre a escola moderna e a contemporânea. Estes autores defendem que é possível compreender uma realidade por meio de uma fotografia, pois ao observar os elementos visuais é possível identificar os operadores do discurso, ou seja, a relação entre o visual e o verbal.

\section{RESULTADOS E DISCUSSÓES}

No início do segundo semestre do ano de 2018, durante o planejamento coletivo, todos os professores e agentes educacionais estavam debatendo sobre as dificuldades dos alunos. Então, a professora A, sugeriu que estava na hora de realizar alguma metodologia diferente para que a escola tivesse mais êxito no processo educativo. Foram suas palavras:

Professor A: Foi durante a hora atividade, todos muito angustiados pois os alunos apresentavam-se estagnados, não estávamos avançando. Nossa escola enfrenta uma realidade difícil com relação a formação e atuação dos professores. Já foi mais complicado pois não tínhamos formação acadêmica. Hoje temos formação, mas atuamos fora da área, com isso dificulta nosso planejamento, pois muitas vezes temos que estudar muito o conteúdo a ser ministrado.

Da fala da professora é possível depreender que tanto ela quanto seus pares encontram dificuldades em atuar nas aulas de outras disciplinas, especialmente naquelas que são completamente fora de sua área de formação inicial. Cabe ressaltar que as turmas da escola são multisseriadas, ou seja, além de um único professor ministrar diferentes disciplinas este precisa lançar mão de abordagens diferentes, uma vez que os estudantes estão em etapas diferentes na mesma turma.

No Quadro, 2 podemos perceber que a quantidade de alunos por turma permite desenvolver um bom trabalho.

Quadro 2: Organização das turmas multisseriadas e quantitativo de alunos

\begin{tabular}{|l|c|}
\hline \multicolumn{1}{|c|}{ Turmas } & Quantidade de alunos \\
\hline Educação Infantil I e II período & 21 alunos \\
\hline $1^{\circ}, 2^{\circ}$ e $3^{\circ}$ ano Ensino fundamental & 18 alunos \\
\hline $4^{\circ}$ e $5^{\circ}$ ano & 23 alunos \\
\hline $6^{\circ}$ e $7^{\circ}$ ano & 16 alunos \\
\hline $8^{\circ}$ e $9^{\circ}$ ano & 17 alunos \\
\hline $1^{\circ}$ e $2^{\circ}$ segmento da EJA fundamental & 12 alunos \\
\hline Ensino Médio regular $\left(1^{\circ}, 2^{\circ}\right.$ e $3^{\circ}$ ano $)$ & 23 alunos \\
\hline Ensino Médio EJA (10 e $2^{\circ}$ ano $)$ & 15 alunos \\
\hline
\end{tabular}

Fonte: Dados coletados na pesquisa (2019). 
Diante deste cenário, os alunos apresentavam dificuldades na aprendizagem e em alguns casos mais graves demonstravam estagnação em relação ao processo educativo. A fim de solucionar tal problema, o grupo de professores resolveu condensar as aulas bimestralmente. O termo 'Condensar' ou 'modular' é utilizado pelos professores para denominar a forma como organizaram as aulas durante $\mathrm{o}$ bimestre, como é possível ser observado no Quadro 3.

Quadro 3: Quantitativo de aulas por turmas multisseriadas

\begin{tabular}{|c|c|c|c|c|c|c|c|c|c|}
\hline Aula & Data & $1^{\circ}, 2^{\circ}$ e $3^{\circ}$ & Disciplina & $4^{\circ}$ e $5^{\circ}$ & Disciplina & $6^{\circ} e 7^{\circ}$ & Disciplina & $8^{\circ}$ e $9^{\circ}$ & Disciplina \\
\hline 1 & $31 / 07 / 19$ & Prof. E & Português & Prof. D & Inglês & Prof. C & Port & Prof. A & Mat \\
\hline 2 & $01 / 08 / 19$ & Prof. E & Português & Prof. D & Inglês & Prof. C & Port & Prof. A & Mat \\
\hline 3 & $02 / 08 / 19$ & Prof. E & Português & Prof. D & Inglês & Prof. C & Port & Prof. A & Mat \\
\hline 4 & $05 / 08 / 19$ & Prof. E & Português & Prof. D & Inglês & Prof. C & Port & Prof. A & Mat \\
\hline 5 & $06 / 08 / 19$ & Prof. E & Português & Prof. D & Inglês & Prof. C & Port & Prof. A & Mat \\
\hline 6 & 07/08/19 & Prof. E & Português & Prof. D & Ciências & Prof. C & Port & Prof. A & Mat \\
\hline 7 & 08/08/19 & Prof. E & Português & Prof. D & Ciências & Prof. C & Port & Prof. A & Mat \\
\hline 8 & 09/08/19 & Prof. E & Geo & Prof. D & Ciências & Prof. C & Port & Prof. A & Mat \\
\hline 9 & $12 / 08 / 19$ & Prof. E & Geo & Prof. D & Ciências & Prof. C & Port & Prof. A & Mat \\
\hline 10 & $13 / 08 / 19$ & Prof. E & Geo & Prof. D & Ciências & Prof. C & Port & Prof. A & Mat \\
\hline 11 & $14 / 08 / 19$ & Prof. E & Geo & Prof. C & Port & Prof. D & Inglês & Prof. A & Artes \\
\hline 12 & $15 / 08 / 19$ & Prof. E & Geo & Prof. C & Port & Prof. D & Inglês & Prof. A & Artes \\
\hline 13 & $16 / 08 / 19$ & Prof. A & Mat & Prof. C & Port & Prof. D & Inglês & Prof. E & Geo \\
\hline 14 & $19 / 08 / 19$ & Prof. A & Mat & Prof. C & Port & Prof. D & Inglês & Prof. E & Geo \\
\hline 15 & $20 / 08 / 19$ & Prof. A & Mat & Prof. C & Port & Prof. D & Inglês & Prof. E & Geo \\
\hline 16 & $21 / 08 / 19$ & Prof. A & Mat & Prof. C & Port & Prof. D & Ciências & Prof. E & Geo \\
\hline 17 & $22 / 08 / 19$ & Prof. A & Mat & Prof. C & Port & Prof. D & Ciências & Prof. E & Geo \\
\hline 18 & $23 / 08 / 19$ & Prof. A & Mat & Prof. C & Port & Prof. D & Ciências & Prof. E & Religiáo \\
\hline 19 & $26 / 08 / 19$ & Prof. A & Mat & Prof. C & Port & Prof. D & Ciências & Prof. E & Religiāo \\
\hline 20 & $27 / 08 / 19$ & Prof. A & Mat & Prof. C & Port & Prof. D & Ciências & Prof. E & Religião \\
\hline 21 & $28 / 08 / 19$ & Prof. D & História & Prof. A & Mat & Prof. E & Geo & Prof. C & Port \\
\hline 22 & $29 / 08 / 19$ & Prof. D & História & Prof. A & Mat & Prof. E & Geo & Prof. C & Port \\
\hline 23 & $30 / 08 / 19$ & Prof. D & História & Prof. A & Mat & Prof. E & Geo & Prof. C & Port \\
\hline 24 & $02 / 09 / 19$ & Prof. D & História & Prof. A & Mat & Prof. E & Geo & Prof. C & Port \\
\hline 25 & $03 / 09 / 19$ & Prof. D & História & Prof. A & Mat & Prof. E & Geo & Prof. C & Port \\
\hline 26 & 04/09/19 & Prof. D & Ciências & Prof. A & Mat & Prof. E & Artes & Prof. C & Port \\
\hline 27 & $05 / 09 / 19$ & Prof. D & Ciências & Prof. A & Mat & Prof. E & Artes & Prof. C & Port \\
\hline 28 & $06 / 09 / 19$ & Prof. D & Ciências & Prof. A & Mat & Prof. E & Religião & Prof. C & Port \\
\hline 29 & 09/09/19 & Prof. D & Ciências & Prof. A & Mat & Prof. E & Religiāo & Prof. C & Port \\
\hline 30 & $10 / 09 / 19$ & Prof. D & Ciências & Prof. A & Mat & Prof. E & Religiāo & Prof. C & Port \\
\hline 31 & $11 / 09 / 19$ & Prof. C & Ed. Física & Prof. E & Geo & Prof. A & Mat & Prof. D & Inglês \\
\hline 32 & $12 / 09 / 19$ & Prof. C & Ed. Física & Prof. E & Geo & Prof. A & Mat & Prof. D & Inglês \\
\hline 33 & $13 / 09 / 19$ & Prof. C & Ed. Física & Prof. E & Geo & Prof. A & Mat & Prof. D & Inglês \\
\hline
\end{tabular}




\begin{tabular}{|c|c|c|c|c|c|c|c|c|c|}
\hline Aula & Data & $1^{\circ}, 2^{\circ}$ e $3^{\circ}$ & Disciplina & $4^{\circ}$ e $5^{\circ}$ & Disciplina & $6^{\circ} \mathrm{e} 7^{\circ}$ & Disciplina & $8^{\circ}$ e $9^{\circ}$ & Disciplina \\
\hline 34 & $16 / 09 / 19$ & Prof. C & Ed. Física & Prof. E & Geo & Prof. A & Mat & Prof. D & Inglês \\
\hline 35 & $17 / 09 / 19$ & Prof. C & Ed. Física & Prof. E & Artes & Prof. A & Mat & Prof. D & Inglês \\
\hline 36 & $18 / 09 / 19$ & Prof. E & Artes & Prof. C & Ed. Física & Prof. A & Mat & Prof. D & Ciências \\
\hline 37 & $19 / 09 / 19$ & Prof. E & Artes & Prof. C & Ed. Física & Prof. A & Mat & Prof. D & Ciências \\
\hline 38 & 20/09/19 & Prof. E & Religião & Prof. C & Ed. Física & Prof. A & Mat & Prof. D & Ciências \\
\hline 39 & 23/09/19 & Prof. E & Religião & Prof. C & Ed. Física & Prof. A & Mat & Prof. D & Ciências \\
\hline 40 & $24 / 09 / 19$ & Prof. E & Religião & Prof. C & Ed. Física & Prof. A & Mat & Prof. D & Ciências \\
\hline 41 & $25 / 09 / 19$ & Prof. E & Português & Prof. D & História & Prof. C & Ed. Física & Prof. A & História \\
\hline 42 & $26 / 09 / 19$ & Prof. E & Português & Prof. D & História & Prof. C & Ed. Física & Prof. A & História \\
\hline 43 & $27 / 09 / 19$ & Prof. E & Português & Prof. D & História & Prof. C & Ed. Física & Prof. A & História \\
\hline 44 & $30 / 09 / 19$ & Prof. E & Português & Prof. D & História & Prof. C & Ed. Física & Prof. A & História \\
\hline 45 & 01/10/19 & Prof. A & Mat & Prof. E & Artes & Prof. D & História & Prof. C & Ed. Física \\
\hline 46 & $02 / 10 / 19$ & Prof. A & Mat & Prof. E & Artes & Prof. D & História & Prof. C & Ed. Física \\
\hline 47 & 03/10/19 & Prof. A & Mat & Prof. E & Religiāo & Prof. D & História & Prof. C & Ed. Física \\
\hline 48 & 04/10/19 & Prof. A & Mat & Prof. E & Religião & Prof. D & História & Prof. C & Ed. Física \\
\hline
\end{tabular}

Fonte: Dados coletados na pesquisa (2019).

Ao observar o Quadro 3, percebe-se que todas as aulas de cada disciplina são ministradas sequencialmente no bimestre (Exemplo: a professora A ministra todas as aulas de matemática em sequência na mesma turma). Fica evidente neste exemplo que ela iniciou as aulas dessa disciplina no dia 31/07/2019 e foi até 13/08/2019 na turma do 8 e $9^{\circ}$ ano do Ensino Fundamenta. Sendo um total de 10 dias com 4 horas aulas, totalizou a carga horária de 40 horas aulas de matemática no $3^{\circ}$ bimestre. $\mathrm{O}$ Quadro 3 também revela uma característica diferente das demais escolas, que é a rotatividade de professores com a turma de $1^{\circ}, 2^{\circ}$ e $3^{\circ}$ ano do Ensino Fundamental.

Ao perguntar aos professores como eles avaliam a forma "modular" que as aulas estão sendo ofertadas na Escola Municipal Sagrado Coração de Jesus, verificouse que:

Professora A: Avalio de forma muito positiva, como estou atuando fora da minha área de formação tenho muitas dificuldades para planejar as aulas. Gasto muito tempo estudando, assistido vídeo aulas procurando as melhores metodologias para cada conteúdo. Consigo fazer um planejamento com mais qualidade. Esse modo permite um contato mais próximo com os alunos. Explico o conteúdo, passo a atividade e já percebo se os alunos compreenderam ou não os conceitos.

Professora E: No meu ponto de vista, tem sido de grande aproveitamento, além de ser uma nova experiência, tendo visto que em todas as escolas que já trabalhei essa é a única que trabalha com sistema modular. Tempo maior na elaboração no planejamento e na execução de nossas atividades.

O posicionamento destes profissionais revela que estão satisfeitos com essa maneira de organizaçáo das aulas, o que náo deixa de ser uma experiência nova para todos. Essa organização permite que os professores acompanhem de forma 
mais próxima a sequência didática para as intervençóes mais imediatas de acordo com cada disciplina. Quanto aos pontos negativos, os professores relataram que náo conseguem identificar nenhum ponto comprometedor.

De acordo com o PPP da escola, a instituição busca ofertar uma Educação do Campo com qualidade, por meio de projetos e com as aulas condensadas/ modular. "O conhecimento deverá ser entendido como um processo de construção e reconstruçáo e, enquanto processo não está pronto, sendo revestido de significado a partir das experiências dos sujeitos-educandos" (PPP, 2016, p. 45). Por isso, é preciso considerar que toda criança, jovem ou adulto ao chegar na escola traz consigo vivências pessoais, familiares e práticas culturais comunitárias e sociais. Esta bagagem deve ser articulada com novos conhecimentos, transformando o saber popular em saber elaborado por meio da ação-reflexão-ação.

Investigados sobre o interesse de manter esse sistema modular para os próximos anos, todos que responderam ao questionário, foram favoráveis. Eles observaram um avanço significativo no processo educativo, principalmente por facilitar o atendimento aos estudantes que se encontram em diferentes etapas de escolarização na mesma turma multisseriada.

Essa constatação confirma estudos similares que, ao observar a Educação do Campo, se depararam com o desafio das turmas multisseriadas, um dos principais desafios enfrentados (ZEFERINO, 2014). Por outro lado, professores que já atuam há tempos nas escolas do campo não enfrentam dificuldades. No presente estudo, a professora E relata que:

Professora E: O seu maior desafio em trabalhar na Educação do Campo, éo fato de trabalhar com turmas multisseriadas, não sendo esse o maior dos problemas ainda encontramos vários alunos com uma grande defasagem de aprendizado, esses alunos fazem parte de uma turma, porem fazem-se necessário fazer um planejamento diferenciado, porque mesmo a sala sendo multisseriada tem criança que não consegue acompanhar nenhuma turma.

Outro aspecto pesquisado neste estudo foi a opinião dos estudantes em relação ao formato das aulas condensadas/modular. Responderam ao questionário 20 estudantes do $4^{\circ}$ e $5^{\circ}$ ano, 15 estudantes do $6^{\circ}$ e $7^{\circ}$ ano e 15 estudantes do $8^{\circ}$ e $9^{\circ}$ ano. Algumas respostas foram selecionadas e seguem apresentadas:

Estudante 7: Esse sistema comparado com o de outras escolas é mais eficaz, pois ajuda os alunos a acompanhar os conteúdos de forma que não fique sobrecarregados. A facilidade de não ter tantas matérias ministradas em pouco tempo causando assim o acumulo de várias atividades

Estudante 8: Com essa rotação mais repetitiva as aulas ficam mais fáceis de acompanhar, ou seja, aprender os conteúdos, do que ter mais de uma disciplina por dia como é o caso de outras escolas. Conseguimos estudar e concluir um certo conteúdo com mais eficácia impulsionando o aprendizado.

Estudante 13: Avalio de forma positiva, pois permite um maior aprofundamento dos conteúdos e atividades em sala de aula. 
Estudante 14: Temos mais tempo para realizar as atividades em sala, com isso mais explicaçôes por parte do professor ou até mesmo de alguns colegas que tem mais facilidade.

A grande maioria dos alunos avaliou como positiva a forma com está organizada a rotina das aulas. No entanto, uma minoria (aproximadamente 10\%) avalia de forma negativa, justificando que:

Estudante 3: No meu ponto de vista não há limitaçôes, mas podemos considerar que as aulas podem se tornar mais cansativas ou enjoativas.

Estudante 4: É uma forma boa, porém as vezes dificulta a realização das atividades que são encaminhadas para casa, pois passa no dia e já temos que trazer respondida no dia seguinte.

Estudante 14: Às vezes o tempo para a entrega de trabalho é curto.

Cabe salientar, na presente reflexáo, uma característica levantada por Marques (2017) de que escola náo necessita se centrar apenas no espaço físico de que dispóe. $\mathrm{O}$ autor considera que existem outros espaços educadores, que extrapolam os muros da escola. As próprias atividades que os alunos presenciam no campo são situaçóes que podem ser utilizadas na construção dos saberes.

De acordo com a maioria dos estudantes, é muito bom continuar com esse modelo, como podemos observar na fala dos mesmos:

Estudante 1: Sim, porque é mais fácil estudar uma disciplina por vez e aprender do que estudar várias disciplinas simultaneamente e o resultado não ser bom.

Estudante 3: Sim, porque estou aprendendo mais, não preciso trazer um monte de livros para escola, e não preciso ficar preocupada com várias provas no mesmo dia.

Estudante 9: Sim, porque é mais fácil estudar e aprender mais. Esse sistema facilita na hora de estudar para as avaliaçôes.

Estudante 13: Creio que sim, pois se torna mais fácil até mesmo para os professores ministrarem as aulas.

Estes resultados estáo em consonância com o estudo de Silva (2018) que observou que, nos últimos anos, os jovens ficaram mais desinteressados pela vida no campo. Por isso a necessidade de tornar a escola atraente é pujante, precisa atender às especificidades do homem do campo e contribuir para a permanência deste na escola e na localidade.

Como se não bastasse, Marques (2017) ainda ressalta que as propostas pedagógicas para as escolas do campo carecem da abordagem da rotina ou contexto dos sujeitos envolvidos. No presentes estudo, a realidade da escola segue retratada e ilustrada por meio de uma fotografia (Figura 1). Trata-se de uma situação do contexto escolar que possibilitou refletir sobre os desafios da Educaçáo do Campo. 
Figura 1: Retrato da Educação do Campo

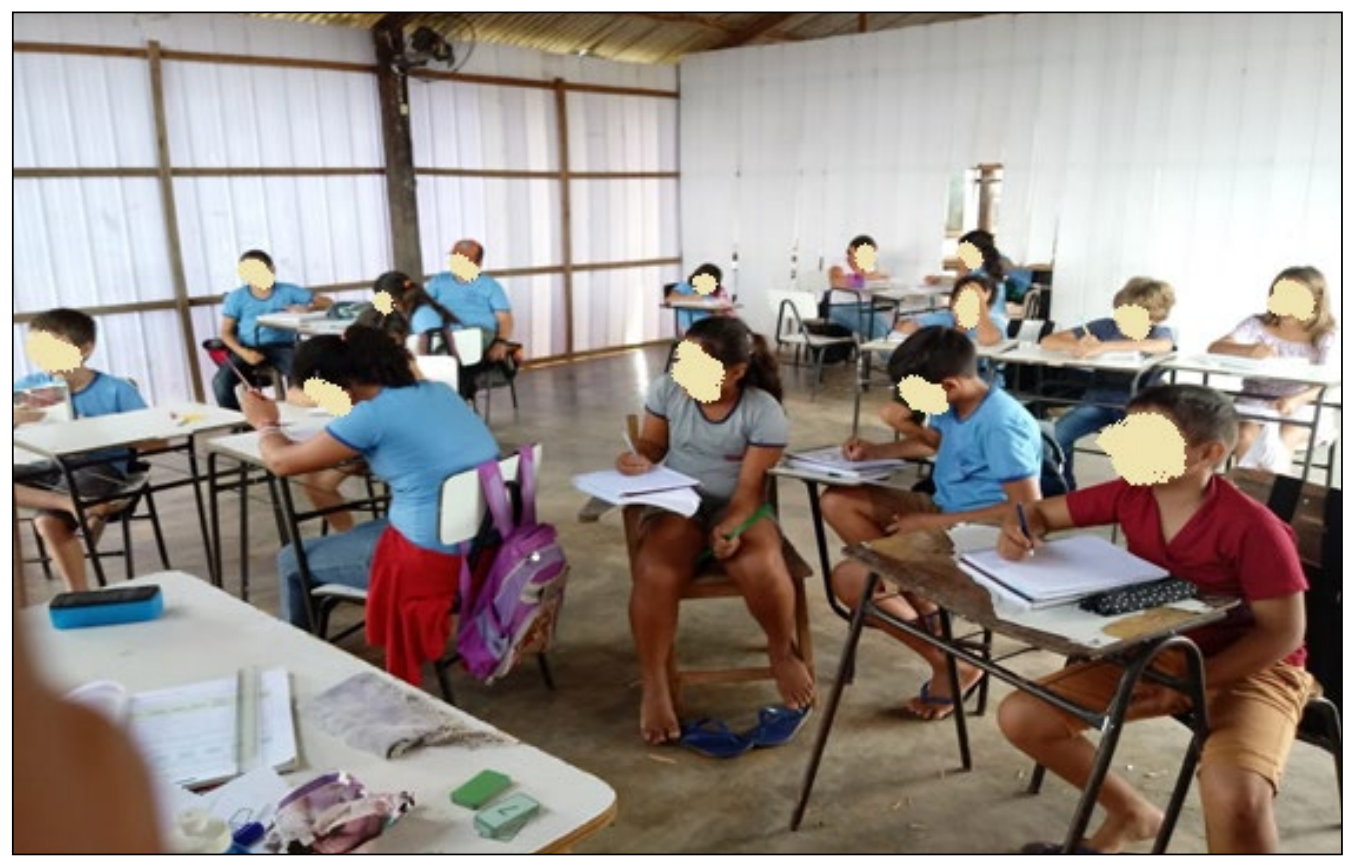

Fonte: Acervo pessoal de Aragão, M. J. (2019).

A fotografia, retratada na Figura 1, é a ilustração de uma sala multisseriada, de $4^{\circ}$ e $5^{\circ}$ ano do Ensino Fundamental, que possui 23 estudantes matriculados. Isto significa que todos estudam em um mesmo ambiente com diferentes níveis de escolarização, sob uma responsabilidade de um único professor. Os alunos são de famílias oriundas de diversos lugares do Brasil, alguns deles embarcam no ônibus escolar por volta das $05 \mathrm{~h} 30$ da manhã e chegam à escola em torno $08 \mathrm{~h} 00$. A aula, via de regra, começa às $08 \mathrm{~h} 00$ e termina às $12 \mathrm{~h} 00$, quando estes estudantes retornam aos seus domicílios.

Alguns professores defendem a heterogeneidade, referente às diferentes etapas de escolarização dos alunos numa mesma turma, como sendo algo produtivo pedagogicamente pelas possibilidade de compartilhamento de saberes que este modelo pode proporcionar Contudo, é preciso considerar outros fatores como a exigência de múltiplos planejamentos, por parte dos professores que precisam atender às inúmeras demandas. Ademais, o aproveitamento nem sempre é satisfatório, pois nem sempre há oportunidade de desenvolver e aplicar as habilidades necessárias. Por isso, o perfil do professor do campo carece ser diferenciado, para que desenvolva um ensino significativo de acordo com o contexto local. Essas constataçóes e críticas são mais recorrentes entre os professores que trabalham com os anos finais do Ensino Fundamental.

As turmas multisseriadas enfrentam, ainda, grandes desafios na Educação do Campo (ZEFERINO, 2014). Essa forma de organização está estritamente vinculada 
ao projeto de desenvolvimento econômico adotado pelo Brasil em suas políticas agrícolas. Tal proposta facilitou a vida dos latifúndios, pois estes mantiveram o trabalhador no campo juntamente com seus familiares uma vez que para 'ler e escrever' esse método é o bastante.

Nesse contexto, pode-se afirmar que os movimentos sociais que lutam pela educaçáo avançaram bastante na conquista de uma educação específica, e digna, que atendesse as demandas do campo. A política projetada pelo agronegócio vem sendo modificada e nos último anos, os governantes vem fornecendo diversos recursos pedagógicos e financeiros para que a escola do campo desenvolva uma proposta pedagógica e metodologias adequadas ao modelo multisseriado. Além desses recursos, também são ofertadas formação de graduaçáo e formaçáo continuada para os professores envolvidos nas propostas pedagógicas que sejam apropriadas para o desenvolvimento do ensino e da aprendizagem voltados as especificidades do campo.

Assim, os profissionais que atuam no campo são as pessoas mais gabaritadas para criar propostas pedagógicas que assegurem um aprendizado de qualidade para os estudantes atendidos pela Educação do Campo, como é o caso da Escola Municipal Sagrado Coração de Jesus, que desde o final de 2008 até os dias atuais oferta as aulas de forma diferenciada.

Ao analisar novamente a Figura 1, verifica-se que este é um ambiente escolar formado por crianças que, aparentemente, estáo fazendo uma atividade em dupla ou grupo. Elas podem, ainda, estar próximas devido ao convívio ou por questáo de afinidade. Observando a estrutura física do espaço, pode-se verificar que este náo foi projetado para ser uma sala de aula. A madeira, ao lado esquerdo da Figura, tem aspecto resistente e as paredes parecem ser improvisadas. Muito provável ser um barracáo que foi adaptado para proteger o espaço interno de ventanias e vendavais, ou outros fenômenos naturais, durante as aulas.

Essa falta de infraestrutura física dos espaços educativos leva a uma triste constatação, em pleno século XXI ainda existam escolas mal equipadas. Estes ambientes devem ser moldados ou reformados, com climatizaçáo e recursos tecnológicos, para proporcionar aos alunos maior conforto e melhor aprendizado. $\mathrm{O}$ ideal seria que fossem construídas salas de aula e laboratórios de alvenaria, espaços com planejamento e conforto visando garantir o bom desempenho dos estudantes que passam quatro horas por dia nestes ambientes. Infelizmente a realidade observada é bem diferente e desconfortável. Essa realidade difere muito daquela relatada por Leão et al. (2014), onde a sala de aula e o contexto retratados apresentam completa estruturaçáo, talvez em função da localidade visto que a escola se situa em área urbana.

No presente estudo, apesar da precariedade da estrutura com móveis desgastados e chão desnivelado observa-se que o lugar é aconchegante. Esse é o retrato da Escola do Campo que funciona em uma comunidade com essa estrutura precária ofertando aulas desde a Educaçáo infantil, Ensino Fundamental, Médio regular até a EJA. Todas as salas são multisseriadas atendendo um público de mais o menos 100 estudantes, entre crianças, adolescentes e adultos. 
Seria ideal atentar-se para a escola do campo como um instrumento de acesso ao conhecimento e à formação cidadá, investindo em políticas públicas que assegurem o que está preconizado na Constituição Federal. O fato de escolas, como a retratada neste estudo, ainda figurarem no descaso governamental sustenta críticas como a levantada por Caldart (2009), de que a educaçáo deve estar de acordo com a realidade dos trabalhadores e trabalhadoras do campo, que possuem igual direito à educaçáo, garantias sociais e vida digna em detrimento dos moradores da zona urbana dos municípios do Brasil. O morador da zona rural é táo munícipe quanto os moradores da cidade.

Outro fator que merece menção, neste estudo, é que a Secretaria Municipal de Educação oferece aos alunos e aos profissionais da educação que trabalham nas escolas do campo duas refeição por dia. Sendo um café da manhã reforçado (com leite e pão, bolo ou biscoitos) e um almoço completo (arroz, feijão, carne e salada). Esta alimentaçáa garante aos envolvidos a energia e o aporte proteico necessários para desempenhar suas funções e é, ainda, um momento de confraternização entre os estudantes.

Além dos detalhes já apresentados, é preciso mencionar que esta unidade escolar precisa de reparos no transporte escolar, na estrutura física das instalaçóes e nos materiais de ensino. Essas demandas nos levam a refletir as palavras de Silva (2018), de que algo precisa ser feito para que náo ocorra o êxodo rural entre os jovens, para que a falta de oportunidade de trabalho remunerado e a educaçáo precária não sejam motivos para que estes procurem novas localidades. Em outras palavras, mesmo que as condiçóes para estudar no campo não sejam as melhores, alguns desafios podem ser vencidos e meios para estimular a permanência e o sucesso escolar dos alunos podem ser desenvolvidos.

\section{CONSIDERAÇÓES FINAIS}

Com o intuito de conhecer a opiniáo de estudantes e professores da Escola Municipal Sagrado Coração de Jesus em relação ao modo como o ensino vem sendo ofertado nas salas multisseriadas, essa investigação permitiu retratar um pouco da realidade dessa escola. Os desafios para otimizar a Educação do Campo são históricos, mas algumas melhorias na infraestrutura e na parte pedagógica podem ser notadas nessas unidades escolares.

$\mathrm{Na}$ escola investigada, a infraestrutura foi mencionada como desfavorável, e a maneira condensada/modular com que as aulas ocorrem foi considerada, por ampla maioria, como algo positivo, até mesmo por facilitar o atendimento a turmas tão heterogêneas. Este estudo também revelou a necessidade do professor que atua nessa modalidade de ensino ter um perfil mais voltado para a rotina do campo. Que este profissional consiga desenvolver atividades condizentes com a realidade do campo facilitando tanto a contextualização dos conteúdos quanto a interação com os estudantes. 
Consideramos que a Educação do Campo está evoluindo em virtude políticas públicas direcionadas ao povo e às demandas das áreas rurais. No entanto, para que a escola seja cada vez mais um lugar de descobertas é preciso reinventar as práticas a fim de assegurar o aprendizado e atender às expectativas. Em outras palavras, devemos criar condiçóes para que os estudantes desenvolvam o senso crítico e se tornem aptos a viverem em uma sociedade com igualdade e dignidade.

Portanto, para trabalhar com os estudantes do campo é preciso não só ter conhecimentos científicos e pedagógicos, mas também precisamos conhecer a realidade local, as famílias que lutam por sobrevivência e qualidade de vida, e as demandas inerentes da vida no campo. Algumas sugestóes podem ser trabalhadas como, por exemplo, elaborar projetos para trabalhar com as famílias locais, investigar a identidade do homem do campo, entre outros. Respeitar e resguardar as características e vividas aliando conhecimento técnico-científico para oportunizar aprendizado e inovação.

\section{REFERÊNCIAS}

BRASIL, Ministério da Educação. Lei 9.394/96. Lei de Diretrizes e Bases da Educação Nacional. Brasília: MEC, 1996. Disponível em: http://www.planalto.gov.br/ccivil_03/leis/ 19394.htm. Acesso em: 17 nov. 2019.

BRASIL, Ministério da Educação. Programa Nacional de Educaçáo do Campo PRONACAMPO. Brasília: MEC, 2013. Disponível em: http://portal.mec.gov.br/index. php?option=com_docman\&view=download\&alias=13214-documento-orientador-dopronacampo-pdf\&Itemid=30192. Acesso em: 17 nov. 2019.

CALDART, Roseli Salet. Por Uma Educaçáo do Campo: traços de uma identidade em construçáo. In: KOLLING. E. J., CERIOLI. P. R., CALDART. R. S. Educação do Campo: identidade e políticas públicas - Coleção Por Uma Educação do Campo, n. ${ }^{\circ} 4$. Brasília: Articulação Nacional Por Uma Educação do Campo, 2002. p. 18-25.

CALDART, Roseli Salet. Educação no Campo: notas para uma análise do percurso. Trab. Educ. Saúde, Rio de Janeiro, v. 7, n 1, p. 35-64, mar/jun., 2009. Disponível em: <http:// www.scielo.br/pdf/tes/v7n1/03.pdf>. Acesso em: 17 nov. 2019.

FREIRE, Paulo. Pedagogia da Autonomia: saberes necessários à prática educativa. São Paulo: Paz e Terra, 2006 (Coleção Leitura).

LEÃO, Marcelo Franco; et al. Reflexões sobre a transiçấo da escola moderna para a contemporânea e sua influência nos processos de ensino e de aprendizagem. Signos, v. 35, p. 88-102, 2014.

LAKATOS, Eva Maria; MARCONI, Marina de Andrade. Fundamentos da metodologia científica. 5. ed. São Paulo: Atlas, 2013.

MARQUES, Luiz Otávio Costa. Interculturalidade na formação de professores do campo: análise de uma experiência. Revista Brasileira de Educaçáo do Campo, v. 2, 
n. 2, p. 447-471, 29 jul. 2017. Disponível em: <https://doi.org/10.20873/uft.25254863.2017v2n2p447>. Acesso em: 08 nov. 2019.

MINAYO, Maria Cecília de S, DESLANDES, Suely Ferreira. Pesquisa social: teoria, método e criatividade. 32. ed. Petrópolis, RJ: Vozes, 2010.

PPP. Projeto Político Pedagógico. Escola Municipal Sagrado Coração de Jesus. Vila Rica: SMEC, 2016.

SILVA, Marizete Andrade da. Interfaces entre a Educação do Campo e o êxodo rural da juventude camponesa. Revista Brasileira de Educaçáo do Campo, v. 3, n. 3, p. 970-990, 7 dez. 2018. Disponível em: <https://doi.org/10.20873/uft.2525-4863.2018v3n3p970>. Acesso em: 08 nov. 2019.

SOUSA, Maria de Lourdes Jorge de; MACHADO, Ilma Ferreira. Educação do Campo, Ensino Médio e juventude camponesa: conceitos em construção. Revista Brasileira de Educaçáo do Campo, v. 3, n. 2, p. 578-595, 27 jul. 2018. Disponível em: <https://doi. org/10.20873/uft.2525-4863.2018v3n2p578>. Acesso em: 08 nov. 2019.

ZEFERINO, Vânia Maria. A Educação do Campo e Seus Desafios. Novas Tebas, 2014. Disponível em: <https://acervodigital.ufpr.br/bitstream/handle/1884/50571/R\%20-\%20 E\%20-\%20VANIA\%20MARIA\%20ZEFERINO.pdf?sequence=1 \&isAllowed=y>. Acesso em: 10 nov. 2019. 